\title{
GÊNERO E DIVERSIDADE SEXUAL NO AMBIENTE ESCOLAR: UMA TRANSVERSALIDADE RELEVANTE
}

\author{
José Carlos de Lima Moura \\ Aluno do $2^{\circ}$ período do Curso de Licenciatura em Geografia do IFRN \\ Pedro Máximo Costa da Silva \\ Aluno do $5^{\circ}$ período do Curso de Bacharelado em Geografia da UFRN \\ Maria Cristina Cavalcanti Araújo \\ Professora Dra do Curso de Geografia do IFRN
}

\section{Resumo}

O presente artigo aborda uma discussão sobre a diversidade sexual, incluindo aspectos da homofobia e seus danos sobre os indivíduos LGBT no ambiente escolar. Propõe uma reflexão sobre o despreparo do corpo docente em relação a não saber intervir e/ou atuar para desmistificar a sexualidade na escola, bem como sobre a falta de interesse dos professores em se aprofundar nesse assunto e na abordagem do mesmo como tema transversal em sala de aula. Levanta pontos sobre a influência da heteronormatividade/sociedade, fazendo com que a escola se silencie e produza um falso discurso de tolerância. 0 caráter desta pesquisa é de natureza bibliográfica. Os objetivos são: colocar em pauta a quebra de tabu sobre gênero e sexualidade na política escolar, levar os professores a uma reflexão, e ampliar os estudos e discussões nessa área com um intuito de uma educação sem preconceitos.

Palavras-Chaves: Escola. Educação. Diversidade Sexual. LGBT.

\section{Abstract}

This article addresses a discussion of sexual diversity, including aspects of homophobia and its harm to LGBT individuals in the school setting. It raises a reflection on the lack of preparation of the faculty in relation to not knowing how to intervene and / or act to demystify the sexuality in the school, as well as on the lack of interest of the teachers to deepen in this subject and the approach of the same like transversal theme in room of class. It raises points about the influence of heteronormativity / society, causing the school to be silent and produce a false tolerance discourse. The character of this research is of a bibliographic nature. The objectives are to put taboo the breaking of taboo on gender and sexuality in the school policy, to lead the teachers to a reflection, and to broaden the studies and discussions in this area with a view to an education without prejudices.

Keywords: School. Education. Sexual Diversity. LGBT. 


\section{INTRODUÇÃO}

Em meio a tantas polêmicas, o movimento LGBT aos poucos vem ganhando espaço social, embora a caminhada em busca de políticas públicas e direitos para a classe tenha grandes barreiras e várias resistências. Historicamente o movimento LGBT entrou em cena no final de 1960 e início da década de 1970, na luta contra a ditadura militar, e, mais tarde, em diálogo com os movimentos sociais nascidos durante o processo de transição para a democracia, na década de 1980. (SANTOS, 2008)

Conforme Santos (2008), a partir de meados de 1990, houve uma abertura gradual da educação para a discussão das relações de gênero no âmbito das políticas públicas. Ou seja, gradativamente o espaço vem sendo conquistado. No Brasil existem muitas barreiras na quebra do preconceito para com a população LGBT, pois, existe um falso discurso da família tradicional abarcado por uma grande maioria que oprime as minorias. Família tradicional esta que é formada segundo os padrões sociais de homem, mulher e filho(s).

Atualmente uma das propostas da classe LGBT é por um ambiente escolar sem preconceitos e que inclua o indivíduo sem nenhum tipo de distinção, uma vez que a homofobia se encontra intrínseca nesse sistema social pautado na visão machista que abole qualquer diferença sexual e de gênero que vá de encontro ao padrão formativo heterossexual hegemônico.

A Escola tem importante função no processo de conscientização, orientação e instrumentalização dos corpos da criança e do adolescente. A instituição escolar, ao classificar os sujeitos pela classe social, etnia e sexo, tem historicamente contribuído para (re) produzir e hierarquizar as diferenças. Essa tradição deixa à margem aqueles que não estão em conformidade com a norma hegemônica e, desta forma, não contempla a inclusão da diversidade sexual, proposta na atualidade. (SANTOS, 2008, P.3).

Tendo em vista que a escola é um local de formação direta, ela é um ambiente primordial para a discussão sobre o LGBT e um ponto de partida para construir uma nova cultura na base e onde as ideias começam a ser formadas. Portanto, a partir a escola, podemos encarar que vivemos em uma realidade, sem se esconder por trás de tradições machistas para não aceitar a grande diversidade sexual, a qual a sociedade não pode oprimir, e sim procurar entender e compreender. Portanto, para reforçarmos a necessidade de inserir o debate do público LGBT na educação.

É necessário que se enfatize algumas medidas, tanto para que haja um tratamento equânime dentro do ambiente escolar, como para uma possibilidade de enfrentamento aos padrões heteronormativos, sexistas e binários, e que que leve a uma possível libertação dos sujeitos que estão encarcerados a essa construção social que se perdura de épocas primitivas. (CAVALCANTE e SILVA, 2014).

Um desafio para o professor é como abordar o tema gênero e diversidade sexual, pois se trata de uma temática escassa de materiais didáticos. Outro fator seria também a falta de conhecimento sobre o assunto. Sendo assim, o pontapé inicial é a busca desse conhecimento por parte desse profissional. 
[...] os/as educadores/as e profissionais em geral terão que, a princípio imediato, adotar medidas estratégicas para implementar no cotidiano práticas que tenham como finalidade o horizonte da emancipação, mesmo diante de todas limitações que são impostas. Isso não quer dizer que essas práticas serão o objetivo último, mas que o cotidiano deve ser encarado para além de um espaço da alienação, mas também de reflexão dos sujeitos. (CAVALCANTE e SILVA, 2014, P.53).

A homofobia não deve ser vista apenas através de uma agressão física, que seria o conceito comum quando se houve falar deste termo. No ambiente escolar, a homofobia é expressa principalmente por meio de agressões verbais, do isolamento e da exclusão. Esses atos causam consequências que podem ser a evasão escolar, o sofrimento e a opressão da vítima. (SANTOS, 2008).

A relevância de se tratar das questões de gênero e diversidade sexual na escola tem um pressuposto importante, que é a formação de identidade do indivíduo, que por muitas vezes sente a necessidade da discussão e compreensão.

Durante os anos de juventude as questões identitárias assumem particular relevo, e o espaço escolar é um ambiente privilegiado das interações dos jovens. Neste contexto, a análise de potenciais impactos do espaço escolar nas identidades sociais dos jovens pode contribuir para uma maior compreensão deste tema. (FERREIRA, 2011, p.45).

Tendo em vista toda uma problemática quando se aborda o tema LGBT, seja em qualquer ambiente social, é preciso frisar sua importância como um tema transversal na escola, pois, é nela que se reproduz todo sistema heteroformativo educacional.

Esse estudo tenta levantar e estimular mais discussões sobre as experiências educacionais que motivem a reflexão para a educação que descentralize o cultivo ultrapassado da heteroxualidade e transforme a escola em um ambiente libertador. Sobre este aspecto, César, Duarte e Sierra (2013) nos mostra que:

A despeito de algumas experiências educacionais especificas e mais recentes definirem novos pressupostos teóricos para abordar as experiências homoeróticas e homoafetivas, a heteronormatividade permanece sendo o centro organizador do governo da sexualidade na escola. (CESAR, DUARTE e SIERRA, 2013, p.197).

De acordo com uma pesquisa realizada por Teixeira-Filho et al (2011), a escola foi o local onde ocorre a maior parte das agressões a indivíduos LGBT, com $61,2 \%$ dos entrevistados; seguido da casa da própria vítima, com $36,7 \%$; e local público (rua, parque, praça, etc.) com $30,6 \%$.

Nessa perspectiva, não podemos negligenciar a importância de engajar na didática de ensino e na pedagogia ações da escola que possam colaborar para a mudança desse quadro, proporcionando a todos, sem distinção, possibilidades diversas para o crescimento pessoal e social. 


\section{A HOMOFOBIA NO AMBIENTE ESCOLAR}

$\mathrm{Na}$ educação, a homofobia se faz presente de diversas formas, inclusive através de ações de intolerância e agressões vindas de uma cultura machista, justificada pela heterossexualidade padronizada por uma sociedade repleta de dogmas e tabus que justificam atos homofóbicos contra os LGBT, reproduzindo raízes de tradição retrógrada.

É em busca de um ambiente escolar e uma sociedade sem homofobia que a população LGBT vem lutando. Para um indivíduo não heterossexual enfrentar a hostilidade e a opressão dentro da escola é uma situação aterrorizante, pois perpassa por muito sofrimento.

Desse modo, no contexto escolar, um local de socialização e que tem por objetivo a promoção dos direitos humanos e da cidadania, ainda encontramos discursos e práticas homofóbicas pelas quais os/ as adolescentes que não se enquadram nos padrões heteronormativos são estigmatizados/as e vitimizados/as por piadinhas homofóbicas, chacotas, insultos, apelidos jocosos, agressões físicas e verbais que visam ao descrédito, sinalizando que ser diferente não é bom e precisa ser punido, a começar pela injúria que produz, na pessoa não-heteronormativizada, um constrangimento que a acompanha por longos períodos de sua vida (ERIBON, 2008, apud, TEIXEIRA-FILHO et al, 2011, p. 728).

Uma das principais formas homofóbicas que podem estar presente nas escolas é a violência simbólica. Essa violência pode ser encontrada, por exemplo, nos materiais didáticos, nas concepções curriculares e nas relações pedagógicas normatizadoras (ALBUQUERQUE e WILLIAMS, 2015). Ou seja, para uma criança ou adolescente é um conflito doloroso se sentir marginalizado em uma representação padronizada pela maioria, na qual ele/ela não se encaixa.

Albuquerque e Williams (2015) retratam que o Instituto Nacional Anísio Teixeira, em um estudo nas escolas públicas do Brasil, constatou que diretores, professores, funcionários, alunos e pais têm atos e religiosidade indicadores de preconceito, onde $72 \%$ são contra homossexuais.

Segundo o Relatório Anual 2013/2014, de Assassinatos de Homossexuais (LGBT) no Brasil, do Grupo Gay da Bahia (GGB), o país permanece ocupando o primeiro lugar em ocorrência de crimes homo-transfóbicos, onde se concentra $40 \%$ dos assassinatos a travestis e transexuais no mundo. Além de ser também constatado um assassinato LGBT a cada 28 horas, vale ressaltar que muitos desses assassinatos são caracterizados tipicamente como os "crimes de ódio" em que prevalece a tortura. (CAVALCANTE e SILVA, 2014, p.54)

A homofobia no ambiente escolar "[...] acontece porque a escola, assim como a sociedade, caracteriza-se por normas rígidas de gênero e sexualidade, como expectativas a respeito da masculinidade, feminilidade e heterossexualidade." (ALBUQUERQUE e WILLIAMS, 2015, p.664). Nenhuma tipificação de violência pode ser justificada, seja ela de que natureza for. A educação não pode se abster de uma posição incisiva na adoção de uma pedagogia libertadora para a promoção da equidade. 


\section{O CORPO DOCENTE E SUA POSIÇÃO AO LGBT NA ESCOLA}

Para o sistema educacional, o professor é enquadrado teoricamente como uma figura onde os alunos buscam o conhecimento, e o seu papel na escola e na sala de aula é promover tal conhecimento, como também estimular ações de pensamentos reflexivos. Muitas vezes o aluno pode recorrer ao professor para discutir sobre sexualidade, porém, nesse contexto, muitas vezes o docente, por alguns motivos, evita esse tipo de conversa, quer por questões ligadas a religiosidade, vergonha, omissão, preconceito, etc.

Vitimizados/as pela homofobia, de forma explícita (agressões físicas e/ou verbais), implícita (ironia, heteronormatividade) ou silenciosa (ausência de discussão sobre diversidade sexual), os/as jovens LGBT's da amostra, tanto quanto os/as ditos/as heterossexuais, ainda que não Ihes seja a primeira opção, buscam os/as professores/ as para debaterem assuntos ligados à sexualidade. (TEIXEIRA- FILHO et al., 2011, p.735).

O que se pressupõe é que os professores não conseguem desvincular suas vidas particulares como costumes, culturas e crenças de suas vidas profissionais. 0 medo de adentrar na perspectiva do desconhecido e que vai além de suas realidades bloqueia a compreensão de se colocar no lugar do outro. "Para experimentar outra lógica, professoras e professores precisam desejar produzir a capacidade para a liberdade, e isso requer elidir as fronteiras do pensamento binário e normativo." (BRITZMAN apud SIERRA e CÉSAR, 2014, p. 42).

Nesse intuito, em 2005, o MEC - Ministério da Educação criou o edital de apoio financeiro à formação continuada a professores e demais profissionais da educação, dentro da temática educação para a cidadania e diversidade sexual (VIANNA, 2015). Uma situação corriqueira é o professor não saber agir, se omitindo em casos de homofobia na escola. De acordo com Albuquerque e Williams (2015), pesquisas retratam que, de acordo com os estudantes, quando existe a ocorrência de bulliyng1 homofóbico, eles não contam com o professor na interferência da agressão. Vianna (2015) diz que, é de grande relevância a promoção aos profissionais da educação, o acesso e implantação de sistemas que os respaldam em pedagogias e materiais didáticos para lidarem adequadamente com a pluralidade sexual.

\section{O SILÊNCIO DA ESCOLA}

A escola reproduz o sistema heteroformativo a partir do momento que se silencia com o discurso de neutralidade e a omissão sobre os atos homofóbicos e achar que ela não é um ambiente para tal assunto, pois, muitas vezes, faz menção de que gênero e diversidade sexual são coisas privadas e particulares e que dizem respeito a cada indivíduo. A escola prefere trabalhar com a maioria, fica mais fácil. Agindo assim, a inclusão é apenas uma teoria. "[...] a mesma escola que cultuava silenciosamente os padrões heteronormativos passa a assumir um posicionamento claro de opressor ao discriminar aquele/a que foi vítima do seu silêncio [...]" (MISKOLCI apud CAVALCANTE e SILVA, 2014, p. 49). 
De acordo com Santos (2008), o ambiente educacional, ao selecionar os alunos por sua classe social, etnia e sexo, só reproduz a divisão das diferenças. Neste contexto, quem não se encaixa na conformidade, fica a margem da hegemonia. Sendo assim, a diversidade sexual não se inclui e a proposta de inclusão atual se resume a teorias não postas em prática.

Portanto, para reforçarmos a necessidade de inserir o debate do público LGBT na educação, será necessário enfatizar medidas tanto para que haja um tratamento equânime dentro do ambiente escolar como uma possibilidade de enfrentamento aos padrões heteronormativos, sexistas e binários para que leve a uma possível libertação dos sujeitos que estão encarcerados a essa construção. (CAVALCANTE e SILVA, 2014, P.48).

É comum o professor em sala de aula não intervir quando presencia um ato de "brincadeira” maldosa (bullyng homofóbico).

Por exemplo, quando um/a aluno/a chama outro/a de veado, bicha, sapatão, os/as professores/as, em vez de proporem uma discussão sobre opressão dos gêneros, estigmas e discriminação, tentam, inversamente, silenciar o discurso com outra opressão, dizendo: Não é permitido falar palavrão em sala de aula!. A homofobia, portanto, exclui e, como tal, gera sofrimento, dor e desesperança aos jovens que se tornam seus alvos (BAKER, 2002, apud, TEIXEIRA-FILHO et al, 2011, p.728).

Conforme Albuquerque e Williams (2015), ao examinar o ambiente escolar por mais de uma década estudando os fatores negativos ao grupo LGBT, constatou-se que a escola é um ambiente opressor para homossexuais, onde $65 \%$ da amostra afırmou que se sente insegura na escola por ter orientação sexual diferente, e $71,3 \%$ citou já ter sido desrespeitado com agressões verbais homofóbicas, ocorrências essas sem nenhum tipo de intervenção da escola.

\section{O LGBT COMO TEMA TRANSVERSAL NA ESCOLA}

A temática gênero e diversidade sexual aos poucos ganha proporção. Enquanto tema transversal interdisplinar, essa temática deve ser explorada por todas as disciplinas do currículo escolar.

Propõe-se que a Orientação Sexual oferecida pela escola aborde com as crianças e os jovens as repercussões das mensagens transmitidas pela mídia, pela família e pelas demais instituições da sociedade. Trata-se de preencher lacunas nas informações que a criança e o adolescente já possuem e, principalmente, criar a possibilidade de formar opinião a respeito do que lhes é ou foi apresentado. A escola, ao propiciar informações atualizadas do ponto de vista científico e ao explicitar e debater os diversos valores associados à sexualidade e aos comportamentos sexuais existentes na sociedade possibilita ao aluno desenvolver atitudes coerentes com os valores que ele próprio eleger como seus. (BRASIL, 1997, p. 300). 
Mesmo com a existência um de um documento que norteia o tema orientação sexual, existem muitas barreiras que contrapõem a liberdade sobre sua discussão dentro das escolas. A escola acaba olhando a temática como conflito, mas precisa encarar os fatos das novas gerações e suas necessidades inclusivas e educacionais. Gerações essas que precisam do apoio da educação plena, sem lacunas de passados que promovem opressão às minorias.

[...] No entanto, as escolas têm dificuldades em compatibilizar, a contento, a complexa relação entre políticas públicas de educação e demandas sociais, pelo menos no que diz respeito às que trata de igualdade de gênero, minimização da homofobia, prevenção às DST/ HIV-AIDS, direitos humanos e temas correlatos. Abordar esses temas torna-se conflitante, pois, inevitavelmente, a escola deverá negociar entre aquilo que as políticas públicas e as leis acreditam ser a direção possível para a produção de cidadãos e cidadãs livres, críticos/as e instruídos/as, e aquilo que os/as professores/as, em suas crenças e valores pessoais, e as famílias, em seus agrupamentos e/ou isoladas, esperam para a educação de seus/suas filhos/as. Trata-se, portanto, de equacionar interesses individuais que se contrapõem aos coletivos. (TEIXEIRA-FILHO et al., 2011, p.727).

Conforme Miskolci apud Cavalcante e Silva (2014), se os sujeitos estão na escola e faz parte de seu corpo escolar, a sexualidade do sujeito faz parte da escola. Assim como o próprio sujeito, a sexualidade não fica em casa ou do lado de fora da escola enquanto os alunos estão na sala de aula. Ela faz parte do aluno 24 horas, o tempo todo.

Segundo Cavalcante e Silva (2014), um dos motivos que leva a escola em não se apropriar do aprofundamento na temática LGBT como tema transversal, é a interferência religiosa que limita a introdução da temática da sexualidade como conteúdo ou discussão que, por sinal, reforça a hegemonia heterossexual, pois limita a visão dos alunos no homem/mulher, desfavorecendo a diversidade sexual e a mulher. "Os conceitos relacionados à sexualidade e aquilo que se valoriza são também produções socioculturais. Como nos demais Temas Transversais, diferentes códigos de valores se contrapõem e disputam espaço." (BRASIL, 1997, P. 307).

Na luta pela introdução de mais frequência do tema LGBT na sala de aula e na escola e na busca por equidade dos sujeitos no ambiente escolar, uma pesquisa do INEP2 citada por Albuquerque e Williams (2015), retrata que a maior prática de bullying e homofobia na escola têm como vítimas os negros e homossexuais.

\section{CONCLUSÕES}

Ao se tratar de diversidade sexual na escola, nota-se que, de acordo com a abordagem de Teixeira-Filho (2011), os alunos carecem de reflexões sobre preconceitos encravados por imposição de uma sociedade machista. Precisa-se criar um cenário escolar crítico com relação à inclusão das minorias que sofrem com a falta de políticas públicas eficazes no combate à homofobia dentro da escola, a qual deveria ser um ambiente inclusivo e sem nenhum tipo de opressão, como reforça Santos (2008), ao alertar que o cenário educacional de combate à homofobia deve advir das ações de construir uma sociedade equânime que subsidia os direitos humanos a todos, sem nenhum tipo de preconceito e distinção, seja ela qual for. 
A falta de posição direta da escola reproduz a exclusão e deixa os indivíduos à margem da sociedade, sofrendo opressões que causam inúmeras consequências, que podem ser temas para futuras pesquisas, como por exemplo, as consequências psicológicas causadas pelo bulliyng homofóbico no ambiente escolar. "Comumente, as sexualidades ditas não hegemônicas são desvalorizadas e hostilizadas, o que causa sofrimento e dor a quem não corresponde aos padrões heteronormativos." (TEIXEIRA-FILHO et al., 2011, p.737).

Podemos pressupor que a cultura heteronormativa tem suas raízes na construção social. É tanto que, até pouco tempo atrás, a visão quanto aos indivíduos LGBT's era de que se tratava de uma doença que justificava a orientação sexual. No entanto, Albuquerque e Williams (2015) cita que na década de 80 a homossexualidade deixa de ser considerada doença pelo Conselho Federal de Psicologia. Dessa forma, passa a ser proibida a intervenção que tenha como objetivo a cura da homossexualidade. Devido aos antecedentes a esse fator, o preconceito de que a diversidade sexual é doença é algo não aceito pelos padrões, porque tudo que foge da maioria e considerado fora do padrão é excluído.

Para finalizar, na perspectiva de Cesar et al (2013), devemos compreender que a educação e os seus processos são um alvo primordial nas lutas sociais. Lutas por meio da inclusão, lutas que prezem políticas públicas que evidenciem a participação dos sujeitos diretamente na dinâmica da sociedade. O caminho para uma educação bem sucedida em todas as instâncias é educar para a emancipação dos discentes; educação reflexiva e crítica sobre imposições do já estabelecido, para ir à busca da liberdade e do bem comum a todos, sem tabus, dogmas e preconceitos.

\section{REFERÊNCIAS}

1. ALBUQUERQUE, Paloma Pegolo de; WILLIAMS, Lúcia Cavalcanti de Albuquerque. Homofobia na escola: relatos de universitários sobre as piores experiências. Temas em Psicologia, v. 23, n. 3, p. 663-676, 2015.

2. BRASIL. Secretaria de Educação. Parâmetros curriculares nacionais: Orientação Sexual / Secretaria de Educação Fundamental. - Brasília: MEC/SEF, p. 285- 336, 1997.

3. CÉSAR, Maria Rita de Assis; DUARTE, André de Macedo; SIERRA, Jamil Cabral. Governamentalização do Estado, movimentos LGBT e escola: capturas e resistências. Educação, v. 36, n. 2, p. 192-200, 2013.

4. SIERRA, Jamil Cabral; CÉSAR, Maria Rita de Assis. Governamentalidade neoliberal e o desafio de uma ética/estética pós-identitária LGBT na educação. Educar em Revista, v. 1, n. 53, p. 35-51, 2014.

5. CAVALCANTE, Francisco Brenno Soares; SILVA, Maria Madalena. Educar para a emancipação humana: o papel atual da escola e a busca por políticas LGBT no ambiente escolar. Revista Periódicus, v. 1, n. 2, p. 44-55, 2014. 
6. COSTA, Ana Alice Alcantara; RODRIGUES, Alexnaldo Teixeira; PASSOS, Elizete Silva. Gênero e diversidades na gestão educacional. Salvador: UFBA-NEIM, 2011. 128 p.

7. FERREIRA, Eduarda. Questões de género e orientação sexual em espaço escolar. SILVA, Joseli Maria; SILVA, Augusto Cesar Pinheiro da. Espaço, Gênero e Poder: conectando fronteiras. Ponta Grossa: Todapalavra, p. 43-65, 2011.

8. LOURO, Guacira Lopes. Gênero, sexualidade e educação: uma perspectiva pósestruturalista. Petrópolis: Rio de Janeiro: Vozes, 6 Ed. 1997.

9. TEIXEIRA-FILHO, Fernando Silva; RONDINI, Carina Alexandra; BESSA, Juliana Cristina. Reflexões sobre homofobia e educação em escolas do interior paulista. Educaçao e Pesquisa: Revista da Faculdade de Educação da Universidade de São Paulo, v. 37, n. 4, p. 725-742, 2011.

10. SANTOS, Claudiene et al. Diversidade sexual na escola e a homofobia: a capacitação de professores como estratégia de intervenção. Fazendo gênero, p. 1-5, 2008.

11. VIANNA, Cláudia Pereira. O movimento LGBT e as políticas de educação de gênero e diversidade sexual: perdas, ganhos e desafios. Educação e Pesquisa, n. ahead, p. 00-00, 2015. 